\title{
Influence of Community-Based Interventions on Routine Immunization Uptake among Children Under Five Years in Ntungamo District-Uganda
}

\author{
Byamukama Topher ${ }^{1,3^{*}}$, Margaret Keraka ${ }^{2}$, Eliphas Gitonga ${ }^{3}$ \\ ${ }^{1}$ Department of Community Health, School of Medicine Kabale University, Box, 317, Kabale, \\ Uganda \\ ${ }^{2}$ Public Health, Kenyatta University, Kenya \\ ${ }^{3}$ Department of Population, Reproductive Health and Community Resource Management
}

\begin{abstract}
Evidence of the effectiveness of community-based interventions in improving immunization coverage in populations of low coverage is limited. Vaccine-preventable diseases is a major public health challenge in low-income countries where Uganda lies, and immunization is the only reliable strategy for child survival. The study's objective was to assess the influence of a community-based intervention on the uptake of immunization services to recommend strategies to health stakeholders to improve immunization coverage. A quasi-experimental study was conducted in three phases. Structured and key informant interviews were used as data collection tools. Phase one provided baseline data before the intervention, the second phase was a community-based intervention, and the third phase was postintervention evaluation. There was no significant difference on the uptake of BCG, POLIO-O, POLIO1, POLIO-2, DPTHeP-Hib1, DPTHeP-Hib2, PCV1 and PCV2 immunizations between the intervention and control group post-intervention $(P=1.00, \alpha=0.5)$. The level of knowledge on immunization was $68.8 \%$ and $29.6 \%$ in the intervention and control groups, respectively. The difference between the two was statistically significant $(P=0.00=\alpha=0.5)$. There was a significant association between the level of knowledge of the caregivers on immunization and the uptake of immunization services $(P=0.00, \alpha=0.5)$. There was also a statistically significant difference in immunization coverage between the intervention and control groups (97.5\%) and (75.1\%) for the intervention and control groups, respectively. The difference was statistically associated with the community-based intervention $(P=0.00, \alpha=0.5)$. Community-based interventions influenced the uptake of routine immunization services.
\end{abstract}

Keywords: Community, Caregivers, Intervention, Immunization, Uptake.

\section{Introduction}

In Africa, every year, more than half-million children die due to vaccine-preventable diseases (VPDs), representing a round $56 \%$ of global death caused by VPDs [1]. According to [2], Uganda is ranked among countries with the highest number of unimmunized children.

Ntungamo district is among 90 districts out of 112 districts in Uganda that have poor access and poor utilization of immunization services, not reaching over $80 \%$ of the children with all recommended doses of childhood vaccinations in accordance with district-specific targets [3]. Ntungamo district has poor access (few children start immunization) and poor utilization (the few who start immunization still few of them do complete), poor access and poor utilization put the district in the fourth category of REC (Reach Every Child) categorization. The national target is category one (good access and good utilization), [3]. The district has low immunization coverage with measles at $64 \%$ and penta 3 at $73 \%$, with some sub-counties having as low as $31 \%$ (measles) and $37 \%$ (penta3), visa vie the required national coverage of $95 \%$ and 
$90 \%$, respectively. The district has a high dropout rate of $14.7 \%$ (penta1- measles), with some health facilities having a dropout rate of up to $89.5 \%$. The national target is below $10 \%$ [4].

The national immunization coverage set goal at the national level is $90 \%$, and at the district level is $80 \%$ with all vaccines [5]. Immunization session is meant to be a one-stop shop for caregivers by receiving all the information and services needed for the child. Vaccinepreventable diseases is a major public health challenge in low-income countries where Uganda lies, and immunization is the only reliable strategy for child survival preventing more than 2.5 million deaths among children [6].

However, despite the growing availability of immunization services, research evaluating the uptake of immunization services indicates low coverage in many countries, Uganda inclusive. Hence, there is a need to understand the barriers to Expanded Programme on Immunization (EPI) implementation, especially in rural areas. Several studies indicate that multiple barriers prevent the successful implementation of EPI programs. These barriers include but are not limited to lack of awareness of the importance of immunization, inadequate knowledge on vaccine-preventable diseases by caregivers, irregular immunization sessions, stock-outs of vaccines and time constraints due to large numbers of caregivers and shortage of health workers. For the successful implementation of EPI to be achieved, many issues need to be considered and put in place. Such issues include detailed knowledge about the local context in which the EPI program is being implemented, an active mechanism that enforce implementation and uptake of immunization services, and local health experts to identify challenges and report them to relevant authorities [7].

Drivers of inequalities in immunization coverage in communities include low education levels of caregivers, religious/cultural beliefs of caregivers, health facility accessibility, topography, social-economic status, and age of caregiver [6].
Vaccination success among children has made it very rare to see a child with polio or measles. However, adverse vaccine reactions and concerns about the safety of the vaccines has been constantly reported in the media and over the internet hence, negatively influencing caregiver's decisions about immunization [8].

Despite the availability of evidence indicating possible remedies to address the challenges of EPI implementation, a number of obstacles still exist especially in sub-Saharan Africa, where resources are a big challenge. The barriers to EPI implementation could impair the ability of an intervention to improve healthcare worker's professional practice. Therefore, identification of these barriers will be the first step in designing health strategies that can help to address them.

Antigens to achieve their full potential, they must reach all children; yet worldwide, one in five children still do not have access to basic vaccines [9]. This study has provided data on the knowledge, cultural practices, and coverage on immunization among children under five years who are the target of the EPI programme. This data is especially useful to the Ministry of Health in planning for child health programme. The community-based interventions have increased caregivers' knowledge on immunization practices which may have contributed to improve their child's health. This complements the Government of Uganda's commitment to achieving universal health coverage status in line with sustainable development goal (SDG) number 3 target 3.2 that seeks to end all preventable deaths under-fives years of age by 2030.

\section{Materials and Methods}

\section{Study Setting and Context}

The study was conducted in Ruhaama and Kajara counties in Ntungamo District. Ntungamo District is bordered to the north by Mitooma and Sheema Districts and Rwampara District, going from west to east. Isingiro District to the east, the Republic of Rwanda to the south, Rukiiga District to the southwest and 
Rukungiri District to the northwest. The district headquarters of Ntungamo are located about $330 \mathrm{~km}$ south-west of Kampala the capital city of Uganda, and about 66 kilometres (41 miles) by road, southwest of Mbarara, the largest city in the Ankole sub-region. The coordinates of the district are: 00 53S, $3016 \mathrm{E}$, and the district covers an area of 2,051.4 square kilometres (792.0 sq miles), of which around $0.2 \%$ is open water, $3.4 \%$ is wetland and close to $0.01 \%$ is forest. The district has 16 government facilities and 1 private not for profit that do conduct deliveries. The district has a population of 491000 people [3].

\section{Study Design}

This was a quasi-experimental study conducted in three phases. In this study, the principal investigator used mixed methods, namely structured interviews and key informant interviews as a data collection tools in assessing the uptake of immunization services by caregivers in Ntungamo. Phase one provided baseline data before the intervention, the second phase was a community-based intervention, and the third phase was post-intervention evaluation. This design was preferred to facilitate testing of the effectiveness of the community intervention by comparing the uptake of immunization services in the control and intervention groups.

\section{Recruitment and Enrollment}

787 caregivers were enrolled for the study, 394 in the intervention arm and 393 in the control arm. The original health educational materials were prepared in English by the immunization experts from District Health Office (DHO) and were translated into the local language (Runyankole) and delivered by health workers with expertise in the area of immunization. In order to get baseline data about immunization, a pre-evaluation survey questionnaire was administered to caregivers in both groups. A community-based intervention was conducted in one of the randomly selected groups, and the second group acted as a control.
The two groups were followed up for nine months, after which a post-evaluation survey was conducted in both groups to evaluate the impact of the intervention.

\section{Study Population}

All mothers/caregivers with children less than two months (0-60 days) in the two selected counties of Ntungamo district. Health facility managers, EPI focal persons and EPI mobilizers were key informants.

\section{Data Collection and Analysis}

\section{Sampling Technique and Sample Size}

\section{Sampling}

Purposive sampling was used to select the two counties where the survey was conducted, while simple random sampling was used to select the county where the intervention took place. All health facilities conducting deliveries were considered for the study (Table 1). A proportional sampling procedure was used to arrive at the study sample from each facility, and systematic random sampling was used to get study participants. The two counties were selected on the basis of having the same socialeconomic and demographic characteristics and both having poor immunization coverage compared to other counties.

\section{Sample Size Estimation}

Sample size calculation (from Whitley and Ball, 2002).

$$
n=\frac{[P 1(1-P 1+P 2(1-P 2)]}{(P 1-P 2) 2} \times c p, \text { Power }
$$

Where:

$$
\begin{aligned}
\mathrm{n}= & \text { number of subjects required } \\
& \text { in each group. } \\
\mathrm{P} 1 \text { and } \mathrm{P} 2= & \text { are proportions in the two } \\
& \text { groups. } \\
\mathrm{cp}, \text { Power }= & \text { is a constant defined by the } \\
& \text { value chosen for the } \mathrm{p} \text { value } \\
& \text { and power }(\mathrm{p} \text { value of } 0.05, \\
& \text { power of } 90 \%, \mathrm{Cp}, \text { Power }= \\
& 10.5) .
\end{aligned}
$$


Considering a recently published health educational intervention on vaccination coverage of children less than 12 months in eastern China [10], the proportion of vaccination coverage was $90 \%(0.9)$ in the intervention group versus $82 \%(0.82)$ in the control group at $90 \%$ power.

The above parameters were to estimate the sample size.

$n=\frac{[0.9(1-0.9)+0.82(1-0.82)]}{(0.9-0.82) 2} \times 10.5=386$
Add $0.2 \%$ refusal/dropouts

$$
N=\frac{N}{1-q}
$$

Where: $\mathrm{N}=$ final sample required, $\mathrm{q}$ is expected refusal/ dropouts.

$$
N=\frac{386}{1-0,02}=394
$$

Therefore, each arm had 394 participants.

Table 1. Expected Deliveries in Health Centres

\begin{tabular}{|l|l|l|}
\hline Ruhaama South County & Expected deliveries (1 month) & Sample needed \\
\hline Kitwe HC1V & 316 & 149 \\
\hline Ruhaama HC111 & 152 & 71 \\
\hline RweikiniroHC111 & 214 & 101 \\
\hline Nyakyera HC111 & 156 & 73 \\
\hline Total & 838 & 394 \\
\hline Kajara County & \multicolumn{2}{|l|}{} \\
\hline Bwongyera HC111 & 212 & 104 \\
\hline Kitondo HC111 & 86 & 42 \\
\hline St. Lucia Kagamba & 66 & 32 \\
\hline Rukoni HC111 & 90 & 44 \\
\hline Rwashamaire HC1V & 238 & 117 \\
\hline IhungaHC111 & 76 & 37 \\
\hline KarurumaHC111 & 38 & 18 \\
\hline Total & 806 & 394 \\
\hline Grand total & 1644 & 788 \\
\hline
\end{tabular}

Source: DHO

\section{Pilot Study}

A pilot study was conducted in a Health Centre in the neighboring Rushenyi County. This was a public health Centre $1 \mathrm{~V}$ in a rural setting similar to the health facilities where the study was done.

\section{Phase One - Baseline Data Collection}

Selected caregivers from health facilities were followed up at home and requested to participant in the survey, having been taken through required consent procedures by the research assistant.

Using the already pretested interview questionnaires, caregivers were interviewed on their knowledge on immunization, cultural and economic factors affecting immunization among others. Qualitative data was collected through key informant interviews which were conducted among the health facility in charges, health facility immunization focal persons and community immunization mobilizers. Caregivers' knowledge on immunization practices was used to gauge the level of knowledge on immunization. Knowledge on immunization practices was categorized as very high, high, moderate, low, and very low. Very high meant that he/she perfectly answered the immunization question and very low meant that he/she had no knowledge about the question. 
Caregivers' perception about immunization was used to establish how the mothers perceive the immunization services provided by the health facilities in their catchment areas. Perception on immunization was categorized as strongly agree, slightly agree, neither agree nor disagree, slightly disagree, and strongly disagree.

\section{Phase Two - Intervention Phase}

The intervention focused on increasing access and utilization of immunization services among the target population. The intervention was based on the identified immunization barriers during the pre-intervention survey, and a robust mixed method was employed.

Village health teams (VHTs) responsible for mobilizing community immunization outreaches were trained and given a responsibility to remind mothers on every gathering opportunity like burials, churches, and other community gatherings about immunization dates for outreaches located in their villages. VHTs also ensured preparation of immunization outreach sites on the day of immunization by bringing seats (benches, chairs, and table) for caregivers and vaccinators, water and soap for hand washing and ensuring social distancing. In addition, health education was conducted in the intervention population targeting caregivers to increase immunization awareness, and the content of the health educational materials was prepared to include the following: the benefits of immunization, diseases prevented by immunization, dangers of partial/incomplete immunization, routine immunization schedule, side effects and contraindications, immunization doses, immunization type and sites.

Validity of content material after the translation was made by a panel of immunization experts from the District Health Office (DHO), and modifications were be made to suit the culture and context of Ntungamo citizens. A half-day seminar was conducted at the parish level in the catchment areas of intervention health facilities for VHTs and at the health facility for vaccinators. The content was delivered through a didactic lecture using flip charts/ manila papers and markers, and at the end, an opportunity was given to participants to ask questions and concerns about immunization and feedback was given. The caregivers in the intervention group were expected to gain better knowledge about immunization in order to increase the vaccine utilization rate.

\section{Phase Three - Post Intervention Evaluation}

This was done nine months after the intervention. The list of names and contacts of the same caregivers who were interviewed at the baseline were given to data collection assistants and again visited for a post-evaluation interview.

Data collection tools used in the baseline study were modified to include all immunizable diseases and used to collect post-intervention data. The level of knowledge on immunization was measured in terms of how the caregivers answered the immunization questions in the post-evaluation questionnaire compared to the baseline survey.

\section{Data Analysis}

Double data entry and validation was done in Epidata then transferred to Stata version 10.0 for analysis. Descriptive analysis and multivariable logistic regression analysis were done. To determine the level of immunization uptake among respondents, the responses given were summarized and computed in percentages for each health facility. The same procedure was used to analyze data on the perceptions and attitudes towards immunization. Mann Whitney U-Test and chi-square tests were used to test the significance of the association between immunization uptake and social-cultural, level of knowledge on immunization services and economic factors, as well as demographic factors.

The odds ratio was used to test the strength of the association of these variables. To establish the effects of a community-based intervention on 
the immunization uptake, a t-test was used to compare the coverage of immunization in the control and intervention groups. Thematic data analysis was used to analyze qualitative data, and it was reviewed in order to identify emerging themes. The analysis involved exploring each thematic area by showing in detail the information relevant to each category, and then data was analysed using content analysis by categorization, summarization and comparison of the study findings and conclusions made based from each theme based on the findings.

Quantitative data was analysed using SPSS version 20. Data was entered and cleaned at the end of each day during the data collection exercise. A descriptive analysis on the independent variables showed mean, median and mode with the deviation standard in relation to the total sample and the levels of skewness and curtosis. A normality test was conducted to see whether data is normally distributed, and this enabled decision was-taking on which statistical test to perform.

Multi-co linearity test was conducted using the Variance Inflation Factor (VIF), which was used to assess multi-co linearity in the regression model. Inferential statistics was used to test the hypothesis of the study and to draw conclusions about the larger population from which the sample size was drawn. The person's chi-square test and Mann Whitney U-Test was used to show the association between dependent and independent variables. A p-value of $<0.05$ was considered statistically significant.

\section{Ethical Considerations}

Approval to conduct the study was given by Kenyatta University Graduate School, and ethical approval was obtained from Kenyatta University Ethics Review Committee.

Clearance to access health facilities was given by the district health officer of Ntungamo. Informed consent to participate in the study was obtained from study respondents, and confidentiality was maintained by ensuring the privacy of the study participants.

\section{Results}

\section{Socio-Demographic Information of Respondents}

The total number of caregivers who participated in the initial survey were 787 with 787 children, giving a response rate of $99.9 \%$. Out of these $94.7 \%$ were married, and $3.7 \%$ were single. Whereas those who participated up to the end of the study was 780, the attrition rate being $0.99 \%$. Children who participated at the beginning of the study were aged between 0 and 60 days old, $53.1 \%$ of them were males while $46.9 \%$ were females.

\section{Level of Knowledge}

This was obtained using Likert scale where V.L stood for Very Low, L for Low, M for Moderate, $\mathrm{H}$ for High and V.H for Very High. The arithmetic means were used to establish the level of knowledge of the caregivers on immunization. This study sought to establish whether the caregivers understood the meaning of the word "Immunization". This was done by requesting the caregivers to give their own definition and understanding of it.

From the definitions, most caregivers (47.1\%) were well conversant (very high) with the meaning of immunization (49.2\% intervention and $45 \%$ control). The arithmetic mean of 4.23 in the intervention versus 3.9 in controls ascertained that the level of knowledge of the caregivers on the definition of immunization was generally high among the intervention than controls. (Table 2).

$18.2 \%$ and $44 \%$ in the intervention and control correctly mentioned above five immunizable diseases. Arithmetic mean of 3.78 versus 3.24 in control and intervention signifies that the level of knowledge of the caregivers on the types of diseases that are immunized against was slightly higher among the control group than the intervention group. (Table 2).

$56.6 \%$ and $75.4 \%$ of the caregivers in the intervention and control groups correctly knew when children should start immunization. The 
arithmetic mean of 4.36 among control versus 3.86 among intervention signifies that the level of knowledge of the caregivers on when a child should start immunization was generally high among control than intervention group (Table 2).

$4.3 \%$ and $29.9 \%$ of the caregivers in the intervention and control groups were very much conversant (very high) with the vaccines names and could tell specifically which disease a particular vaccine prevents. Arithmetic mean of 2.23 and 3.18 among intervention and control groups respectively, signifies that the level of knowledge of the caregivers on the vaccines that a child receives during immunization was generally high among the control than the intervention (Table 2).

$10.9 \%$ of the caregivers in the intervention and $33.8 \%$ of the caregivers in the control were very much conversant with the immunization schedule of their children. Arithmetic mean of 2.27 among intervention and 2.91 among the control group signifies that the level of knowledge of the caregivers on the routine immunization schedule of a child was generally good among the control as compared to intervention group (Table 2).

Table 2. The Caregivers Level of Knowledge on Immunization

\begin{tabular}{|c|c|c|c|c|c|c|c|}
\hline \multirow[t]{2}{*}{ Statements } & & V.L & $\mathbf{L}$ & $\mathbf{M}$ & H & V.H & \multirow{2}{*}{$\begin{array}{l}\text { Mean } \pm \\
\text { S.D }\end{array}$} \\
\hline & & $\mathrm{F}(\%)$ & $\mathrm{F}(\%)$ & $\mathrm{F}(\%)$ & $\mathrm{F}(\%)$ & $\mathrm{F}(\%)$ & \\
\hline \multirow{2}{*}{$\begin{array}{l}\text { Knowledge on } \\
\text { the meaning of } \\
\text { immunization }\end{array}$} & $\mathbf{I}$ & $18(4.5)$ & $14(3.5)$ & $20(5.1)$ & $149(37.6)$ & $195(49.2)$ & $4.23 \pm 1.02$ \\
\hline & $\mathrm{C}$ & $47(12)$ & $13(3.3)$ & $49(12.5)$ & $106(27.1)$ & $176(45)$ & $3.90 \pm 1.34$ \\
\hline \multirow[b]{2}{*}{$\begin{array}{l}\text { Knowledge on at } \\
\text { least five diseases } \\
\text { that are } \\
\text { immunized } \\
\text { against }\end{array}$} & I & $77(19.4)$ & $49(12.4)$ & $44(11.1)$ & $154(38.9)$ & $72(18.2)$ & $3.24 \pm 1.40$ \\
\hline & $\mathbf{C}$ & $49(12.5)$ & $33(8.4)$ & $45(11.5)$ & $92(23.5)$ & $172(44)$ & $3.78 \pm 1.41$ \\
\hline \multirow{2}{*}{$\begin{array}{l}\text { Knowledge on } \\
\text { when a child } \\
\text { should start } \\
\text { immunization }\end{array}$} & I & $81(20.5)$ & $15(3.8)$ & $7(1.8)$ & $69(17.4)$ & $224(56.6)$ & $3.86 \pm 1.60$ \\
\hline & $\mathrm{C}$ & $39(10)$ & $13(3.3)$ & $12(3.1)$ & $32(8.2)$ & $295(75.4)$ & $4.36 \pm 1.30$ \\
\hline \multirow{2}{*}{$\begin{array}{l}\text { Knowledge on at } \\
\text { least five } \\
\text { vaccines that a } \\
\text { child receives } \\
\text { during } \\
\text { immunizations. } \\
\end{array}$} & I & $172(43.4)$ & $70(17.7)$ & $62(15.7)$ & $75(18.9)$ & $17(4.3)$ & $2.23 \pm 1.30$ \\
\hline & $\mathbf{C}$ & $97(24.8)$ & $48(12.3)$ & $52(13.3)$ & 77(19.7) & $117(29.9)$ & $3.18 \pm 1.58$ \\
\hline \multirow{2}{*}{$\begin{array}{l}\text { Knowledge on } \\
\text { the benefits of } \\
\text { immunization }\end{array}$} & I & $36(9.1)$ & $21(5.3)$ & $45(11.4)$ & $215(54.3)$ & 79(19.9) & $3.71 \pm 1.12$ \\
\hline & $\mathbf{C}$ & $49(12.5)$ & $35(9)$ & $56(14.3)$ & $136(34.8)$ & $115(29.4)$ & $3.60 \pm 1.33$ \\
\hline \multirow{2}{*}{$\begin{array}{l}\text { Knowledge on } \\
\text { the routine } \\
\text { immunization } \\
\text { schedule of a } \\
\text { child }\end{array}$} & I & $191(48.2)$ & $65(16.4)$ & $26(6.6)$ & 71(17.9) & $43(10.9)$ & $2.27 \pm 1.48$ \\
\hline & $\mathbf{C}$ & 148(37.9) & $33(8.4)$ & $50(12.8)$ & $28(7.2)$ & 132(33.8) & $2.91 \pm 1.74$ \\
\hline
\end{tabular}


Social Cultural and Economic Factors of Caregivers that Affect the Uptake of Immunization Services

\section{Social Cultural Factors/Challenges Affecting Immunization Uptake}

From the study, only $22.7 \%$ of the caregivers could not establish any social-cultural factors or challenges that directly hindered their uptake of immunization services, while majority of them (77.3\%) were affected by some of these challenges. $17.3 \%$ of the caregivers reported sickness (mother/ child) as one of the challenges that affected the caregivers' immunization uptake, while $15.1 \%$ of the caregivers mentioned domestic violence as challenge that posed a threat to the uptake of immunization services (Fig.1). This was evidenced by the Key Informant Interview (KII), where one of the EPI focal persons said "there is lack of male involvement in immunization services because men do not care about immunization and even some beat up their wives after coming back from immunization session, claiming that they delay on the way or get involved into other things claiming that they have gone for immunization and this has led to high dropout rates on immunizations".

$12.6 \%$ and $11.3 \%$ of the caregivers reported Outbreak of COVID-19 and drunkardness as the challenges that affected the uptake of immunization services (Fig.1). This was confirmed during the KII where one of the EPI mobilizers had to say" most of the men in this community are alcoholic, they spent most of their time on bars drinking, and they don't support their wives at all, in fact they do not mind whether their children are immunized or not.

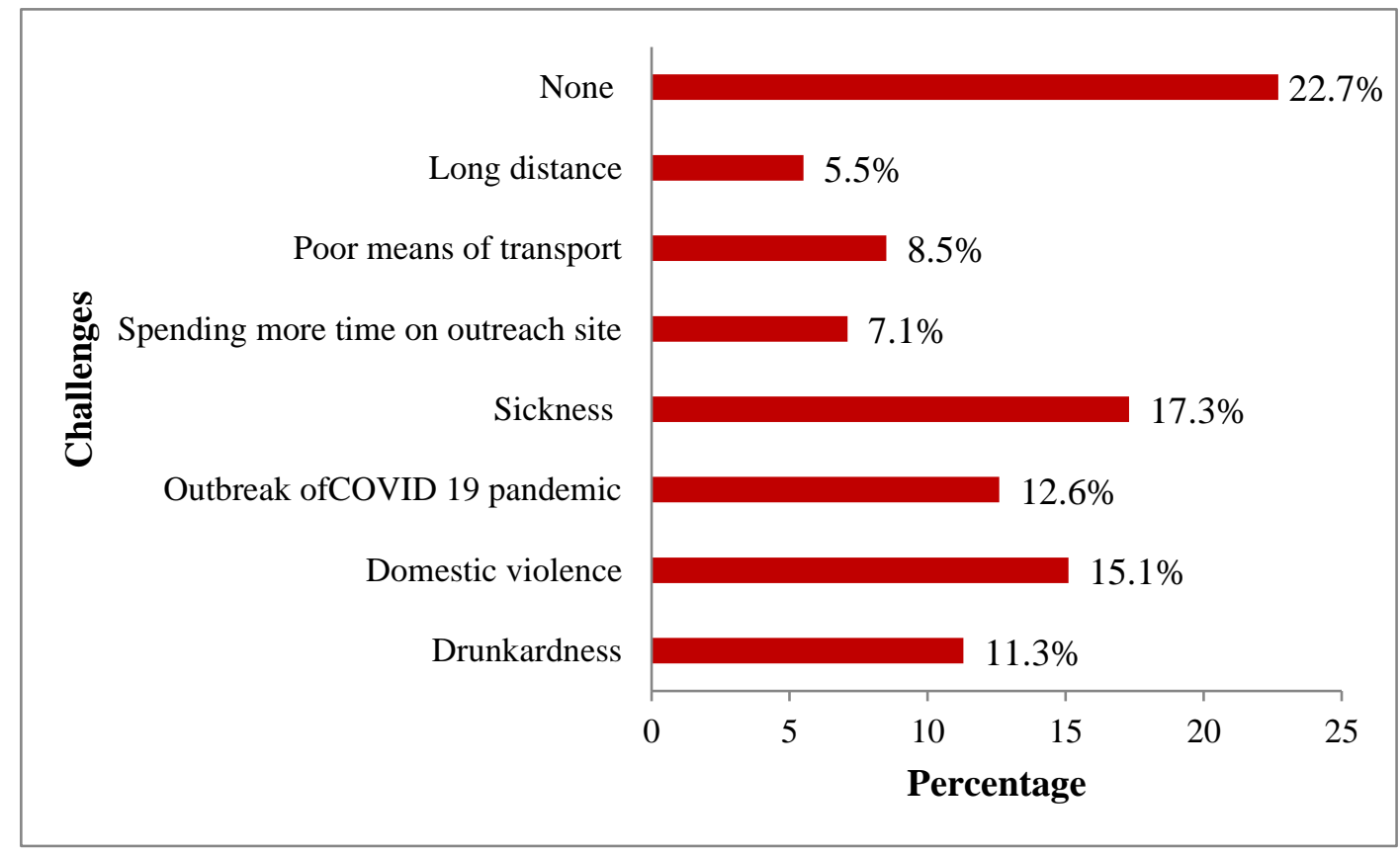

Figure 1. Social-cultural Factors/ Challenges Affecting Immunization Uptake

\section{Cultural Activities used as a} Substitute/Alternative to Immunization

From the study, most of the caregivers $(64.3 \%)$ never had any cultural activities which were used as a substitute or alternative to immunization while $35.8 \%$ of them did. Of those who had such alternatives, $25.9 \%$ of them used local herbs, while $9.9 \%$ of them obtained lucky rings form witch doctors and put them on their children. They still believed on such acts due to lack of exposure and lack of sensitization on the significance of immunization services (Fig.2). This was confirmed during KII by one of the EPI mobilizers who said "some few mothers still believe in these local things like protective herbs 
from local herbalist (emibaaziyekiraguju- local dialect) that protects their children from diseases including immunizable ones, some do not immunize even due to the religion they believe in for example those who belong to "Basisimuki" religious sect do not believe in immunization".

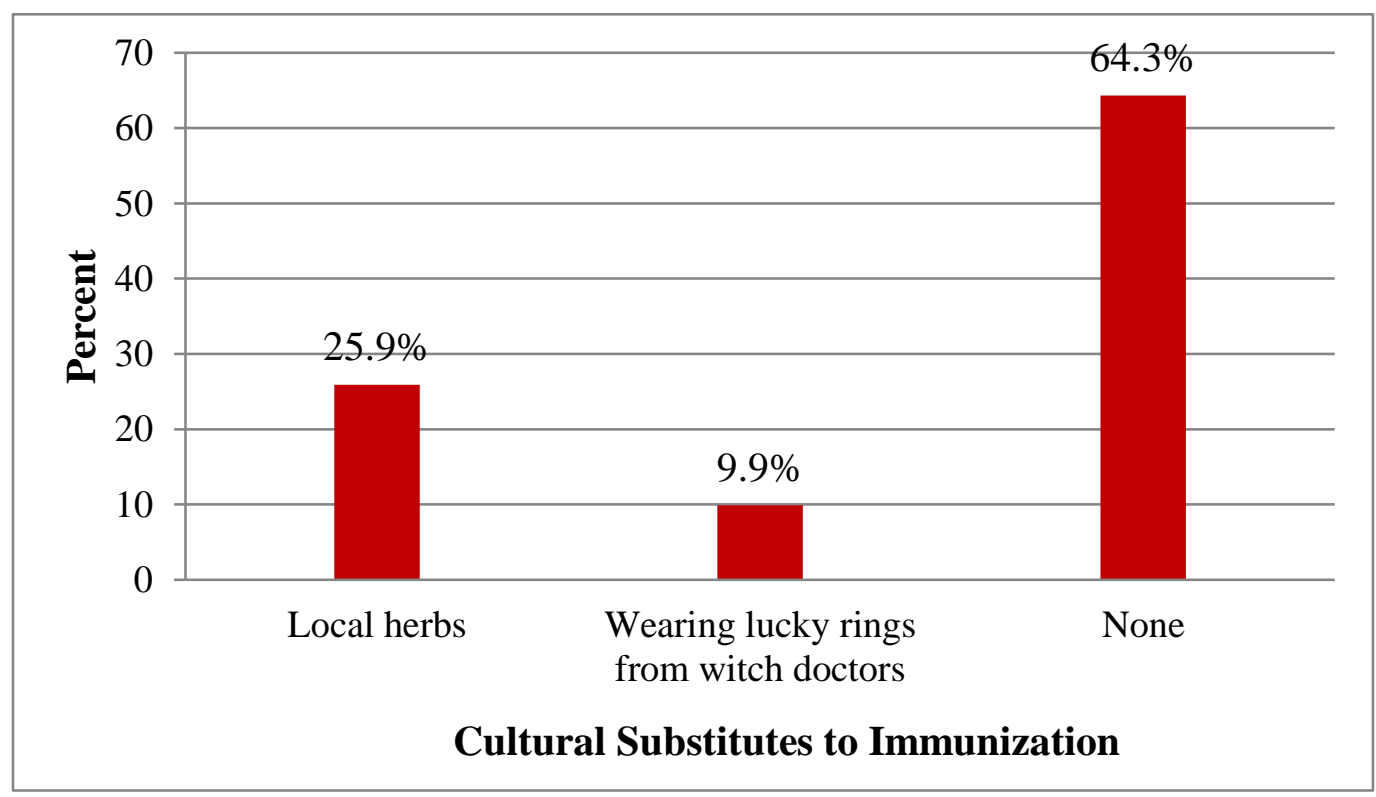

Figure 2. Cultural Activities used as a Substitute/ Alternative to Immunization

\section{Cultural Beliefs/Taboos about Immunization}

From the study, most of the caregivers (65\%) had cultural beliefs/taboos about immunization while $35 \%$ of them had none. Most of the caregivers $(40.4 \%)$ believed that immunization leads to infertility for their children in the future, while $24.7 \%$ of them believed that immunization causes death in children (Fig. 3). All these untrue cultural beliefs/taboos about immunization are as a result of a lack of proper sensitization of the caregivers about the benefits of immunization to their children. This was evidenced during KII by one of the health facilities in charge had this to say, "there is lack of community dialogues due to inadequate funding for EPI activity by the government".

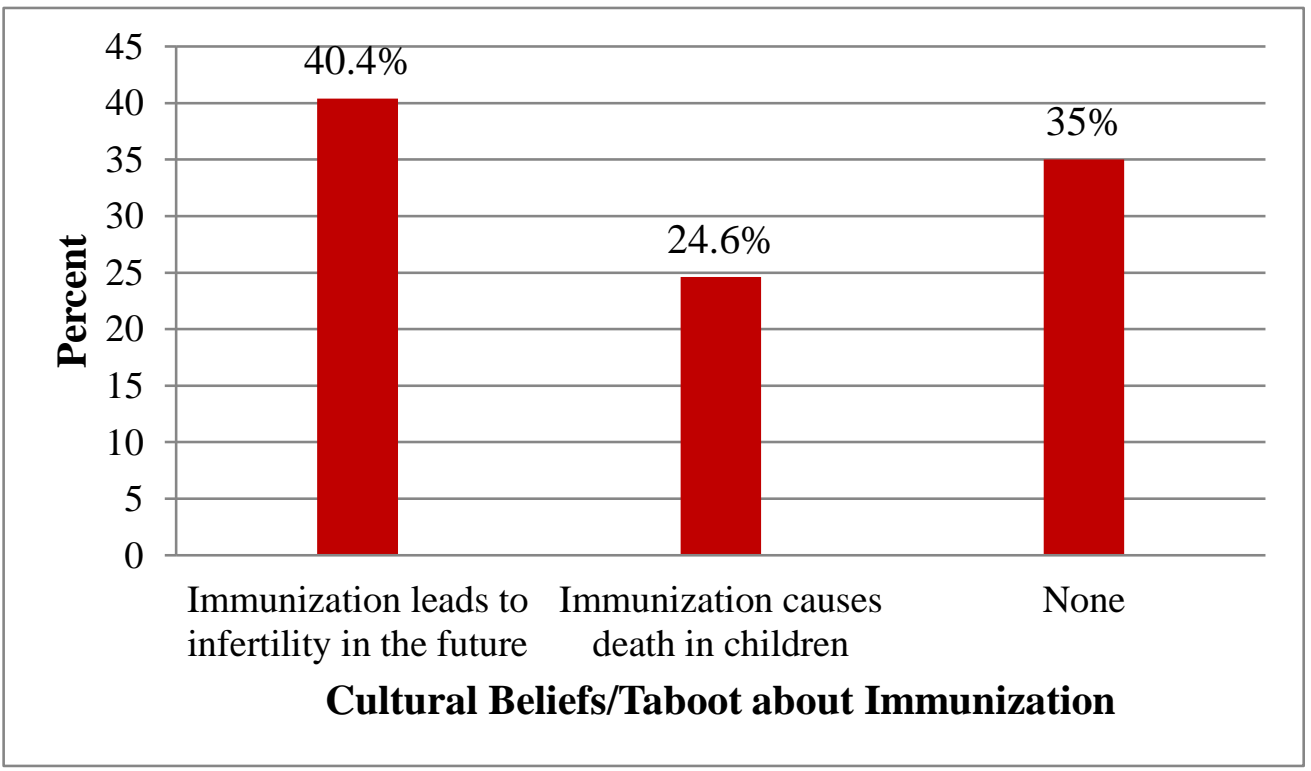

Figure 3. Cultural beliefs/Taboos about Immunization 


\section{Economic Factors/Challenges Affecting Immunization Uptake}

(63.7\%) of the caregivers had faced economic challenges that had interfered with their uptake of immunization services while $36.3 \%$ of them had not. One of the economic challenges faced by the caregivers that hindered their uptake of immunization services was lack of finances for transport (Fig.4). This was confirmed by the KII one of the EPI focal persons at a health facility who said "mothers travel long distances on foot to access immunization services here, and this affects the turn up and increases our dropout rate as a health facility".

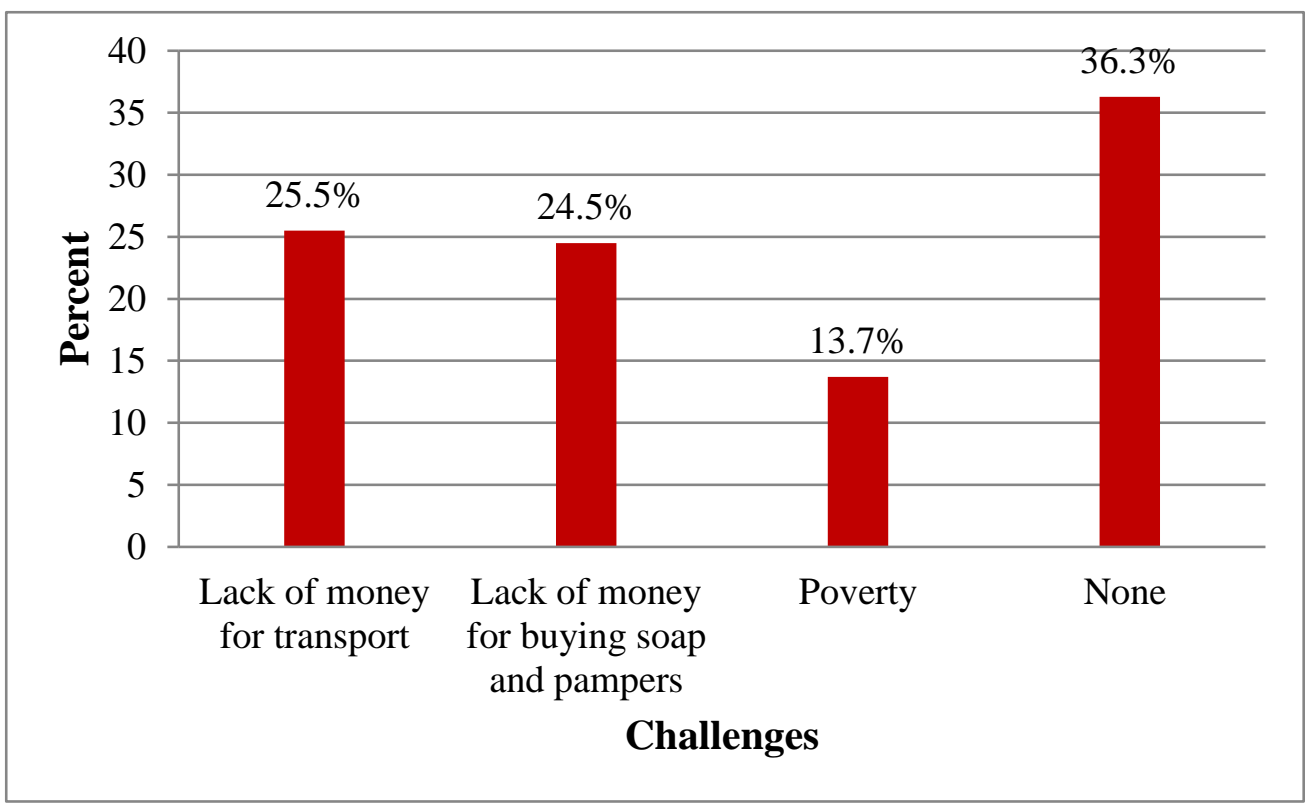

Figure 4. Economic Factors/ Challenges Affecting Immunization Uptake

\section{Post Intervention Results}

\section{Demographic Information of children}

On the gender distribution of children, most of them were males in both intervention and control groups (50.9\% for each). On children's life, $99.7 \%$ of children were still alive after the intervention period while $0.3 \%$ of them died during the same period within the intervention group, whereas on the control group, $98.5 \%$ of children were still alive after the intervention period while $1.5 \%$ of them died during the same period. On children's age, most of the children on the intervention group (31.6\%) were 10 months old after the elapse of the intervention period, while the majority of the children on the control group (37.7\%) were aged 11 months after the elapse of the same period (Table 3).

Table 3. Demographic Information of Children

\begin{tabular}{|l|l|l|l|l|l|}
\hline \multicolumn{2}{|c|}{} & \multicolumn{2}{l|}{ Intervention } & Control \\
\cline { 3 - 7 } \multicolumn{2}{|c|}{} & Frequency & Percentage & Frequency & Percentage \\
\hline \multirow{3}{*}{ Child's Life } & Live & 395 & 99.7 & 385 & 98.5 \\
\cline { 2 - 6 } & Dead & 1 & 0.3 & 6 & 1.5 \\
\cline { 2 - 6 } & Total & $\mathbf{3 9 6}$ & $\mathbf{1 0 0}$ & $\mathbf{3 9 1}$ & $\mathbf{1 0 0}$ \\
\hline \multirow{3}{*}{ Child's Age (Months) } & 9 Months & 67 & 17 & 7 & 1.8 \\
\cline { 2 - 6 } & 10 Months & 125 & 31.6 & 41 & 10.6 \\
\cline { 2 - 6 } & 11 Months & 81 & 20.5 & 145 & 37.7 \\
\cline { 2 - 6 } & 12 Months & 67 & 17 & 126 & 32.7 \\
\hline
\end{tabular}




\begin{tabular}{|l|l|l|l|l|l|}
\hline & 13 Months & 50 & 12.7 & 61 & 15.8 \\
\cline { 2 - 6 } & 14 Months & 5 & 1.3 & 1 & 1.3 \\
\cline { 2 - 6 } & Total & $\mathbf{3 9 5}$ & $\mathbf{1 0 0}$ & $\mathbf{3 8 5}$ & $\mathbf{1 0 0}$ \\
\hline \multirow{4}{*}{ Child's Gender } & Male & 201 & 50.9 & 196 & 50.9 \\
\cline { 2 - 6 } & Female & 194 & 49.1 & 189 & 49.1 \\
\cline { 2 - 6 } & Total & $\mathbf{3 9 5}$ & $\mathbf{1 0 0}$ & $\mathbf{3 8 5}$ & $\mathbf{1 0 0}$ \\
\hline
\end{tabular}

\section{Immunization Uptake}

On BCG, POLIO 0, POLIO 1, POLIO 2, DPTHeP-Hib1, DPTHeP-Hib2, PCV1 and PCV2 immunizations, all the children in both the intervention and control groups received the above vaccines within the intervention period. However, on POLIO 3, DPTHeP-Hib3 and PVC3 immunizations, 99\% of the children in the intervention group received the vaccines as compared to $87.3 \%$ of the children in the control group. On IPV, $99 \%$ of the children in the intervention group received IPV vaccine as compared to $88.6 \%$ of the children in the control group. On Vitamin A, $16.5 \%$ of the children in the intervention group never received it as compared to $42.3 \%$ of the children in the control group. On Meascles, $98.2 \%$ of the children in the intervention group received measles vaccine compared to $73.8 \%$ of the children in the control group (Table 4).

Table 4. Immunization Uptake of Various Antigens Post Intervention

\begin{tabular}{|c|c|c|c|c|c|}
\hline \multirow[t]{2}{*}{ Immunizations } & \multirow[t]{2}{*}{ Response } & \multicolumn{2}{|c|}{ Intervention } & \multicolumn{2}{|l|}{ Control } \\
\hline & & Frequency & Percentage & Frequency & Percentage \\
\hline \multirow[t]{3}{*}{ BCG } & Yes & 395 & 100 & 385 & 100 \\
\hline & No & 0 & 0 & 0 & 0 \\
\hline & Total & 395 & 100 & 385 & 100 \\
\hline \multirow[t]{3}{*}{ POLIO 0} & Yes & 395 & 100 & 385 & 100 \\
\hline & No & 0 & 0 & 0 & 0 \\
\hline & Total & 395 & 100 & 385 & 100 \\
\hline \multirow[t]{3}{*}{ POLIO 1} & Yes & 395 & 100 & 385 & 100 \\
\hline & No & 0 & 0 & 0 & 0 \\
\hline & Total & 395 & 100 & 385 & 100 \\
\hline \multirow[t]{3}{*}{ POLIO 2} & Yes & 395 & 100 & 385 & 100 \\
\hline & No & 0 & 0 & 0 & 0 \\
\hline & Total & 395 & 100 & 385 & 100 \\
\hline \multirow[t]{3}{*}{ POLIO 3} & Yes & 391 & 99 & 336 & 87.3 \\
\hline & No & 4 & 1 & 49 & 12.7 \\
\hline & Total & 395 & 100 & 385 & 100 \\
\hline \multirow[t]{3}{*}{ DPTHeP-Hib1 } & Yes & 395 & 100 & 385 & 100 \\
\hline & No & 0 & 0 & 0 & 0 \\
\hline & Total & 395 & 100 & 385 & 100 \\
\hline \multirow[t]{3}{*}{ DPTHeP-Hib2 } & Yes & 395 & 100 & 385 & 100 \\
\hline & No & 0 & 0 & 0 & 0 \\
\hline & Total & 395 & 100 & 385 & 100 \\
\hline \multirow[t]{2}{*}{ DPTHeP-Hib3 } & Yes & 391 & 99 & 336 & 87.3 \\
\hline & No & 4 & 1 & 49 & 12.7 \\
\hline
\end{tabular}




\begin{tabular}{|l|l|l|l|l|l|}
\hline & Total & $\mathbf{3 9 5}$ & $\mathbf{1 0 0}$ & $\mathbf{3 8 5}$ & $\mathbf{1 0 0}$ \\
\hline \multirow{5}{*}{ PCV1 } & Yes & 394 & 100 & 385 & 100 \\
\cline { 2 - 6 } & No & 0 & 0 & 0 & 0 \\
\cline { 2 - 6 } & Total & $\mathbf{3 9 4}$ & $\mathbf{1 0 0}$ & $\mathbf{3 8 5}$ & $\mathbf{1 0 0}$ \\
\hline \multirow{5}{*}{ PCV2 } & Yes & 395 & 100 & 385 & 100 \\
\cline { 2 - 6 } & No & 0 & 0 & 0 & 0 \\
\cline { 2 - 6 } & Total & $\mathbf{3 9 5}$ & $\mathbf{1 0 0}$ & $\mathbf{3 8 5}$ & $\mathbf{1 0 0}$ \\
\hline \multirow{5}{*}{ IPV } & Yes & 391 & 99 & 336 & 87.3 \\
\cline { 2 - 6 } & No & 4 & 1 & 49 & 12.7 \\
\cline { 2 - 6 } & Total & $\mathbf{3 9 5}$ & $\mathbf{1 0 0}$ & $\mathbf{3 8 5}$ & $\mathbf{1 0 0}$ \\
\hline \multirow{5}{*}{ VITAMIN A } & Yes & 391 & 99 & 341 & 88.6 \\
\cline { 2 - 6 } & No & 4 & 1 & 44 & 11.4 \\
\cline { 2 - 6 } & Total & $\mathbf{3 9 5}$ & $\mathbf{1 0 0}$ & $\mathbf{3 8 5}$ & $\mathbf{1 0 0}$ \\
\cline { 2 - 6 } & Yes & 330 & 83.5 & 222 & 57.7 \\
\cline { 2 - 6 } & No & 65 & 16.5 & 163 & 42.3 \\
\cline { 2 - 6 } & Total & $\mathbf{3 9 5}$ & $\mathbf{1 0 0}$ & $\mathbf{3 8 5}$ & $\mathbf{1 0 0}$ \\
\hline \multirow{5}{*}{ MEASLES } & Yes & 387 & 98.2 & 284 & 73.8 \\
\cline { 2 - 6 } & No & 7 & 1.8 & 101 & 26.2 \\
\cline { 2 - 6 } & Total & $\mathbf{3 9 4}$ & $\mathbf{1 0 0}$ & $\mathbf{3 8 5}$ & $\mathbf{1 0 0}$ \\
\hline
\end{tabular}

\section{Effect of Community-based Intervention on the Level of Knowledge on Immunization}

The same questions that were administered during the initial survey on the level of knowledge on immunization were again asked in the post-intervention. On the meaning of immunization, the caregivers were requested to give their own definition and understanding of it. The level of knowledge on the meaning of immunization for most of the caregivers on the intervention group on very high increased from $49.2 \%$ to $71.4 \%$, while in control increased from $45 \%$ to $49.6 \%$ before and after intervention, respectively (Table 5). Equally, arithmetic mean of 4.66 and 3.11 for the intervention and control groups respectively acknowledged that the level of knowledge of the caregivers on the meaning of immunization was generally very high amongst the ones on the intervention group and moderate for the caregivers in the control group (Table 5).

On the diseases that are immunized against, the caregivers were requested to mention at least five of the immunizable diseases. The level of knowledge on the diseases immunized against, on the scale of very high, in the intervention group, increased from $18.2 \%$ to $67.1 \%$, while in the control group decreased from $44 \%$ to $24.9 \%$ before and after the intervention, respectively (Table 5). Similarly, the arithmetic mean of 4.62 and 3.14 for the intervention and control groups respectively signified that the level of knowledge of the caregivers on the diseases that are immunized against was generally very high amongst the intervention group as compared to control group (Table 5).

On when a child should start immunization, the caregivers were requested to give their responses based on the timelines they thought was correct to start immunizing their children. The level of knowledge on the timelines for most of the intervention group caregivers increased from $56.6 \%$ to $66.8 \%$, while in control decreased from $75.4 \%$ to $52.4 \%$ before and after the intervention, respectively (Table 5). Likewise, arithmetic mean of 4.61 and 3.15 for the same subject on the intervention and control groups respectively asserted that the level of knowledge of on when a child should start immunization was generally very high and moderate amongst 
caregivers in the intervention and control group, respectively (Table 5).

On the vaccines that a child receives during immunization, the caregivers were requested to state at least five vaccines that a child receives during immunization. The level of knowledge of most of the caregivers on the vaccines on very high increased from $4.3 \%$ for the intervention group to $64.2 \%$, while in control increased from $29.9 \%$ to $31.2 \%$ before and after the intervention, respectively (table 5). On the same note, arithmetic mean of 4.57 and 3.05 for the vaccine knowledge for intervention and control groups respectively signified that the level of knowledge of the caregivers on the vaccines that a child receives during immunization was generally very high for the ones on the intervention group compared to the control group ones (Table 5).

On the benefits of immunization, the caregivers were requested to state the benefits associated with immunization that they were aware of. The level of knowledge of most of the caregivers on these benefits for the intervention group on very high increased from $19.9 \%$ to $67.3 \%$ and in control from 29.4 to $35.2 \%$ before and after the intervention, respectively (Table 5). Equally, the arithmetic mean of 4.62 and 3.05 for the immunization benefits for intervention and control groups respectively signified that the level of knowledge on benefits of immunization was generally very high for the caregivers in the intervention than the control group.
On why a child should be taken for immunization, the caregivers were requested to state the reasons as to why they take their children for immunization. The level of knowledge on the reasons for immunization on most of the caregivers on the intervention group $(66.3 \%)$ was very high and moderate for most of the caregivers $(51.7 \%)$ on the control group (Table 5). Similarly, the arithmetic mean of 4.63 and 3.01 for the intervention and control groups respectively on the same subject acknowledged that the level of knowledge of the caregivers on why a child should be taken for immunization was generally very high and moderate for the caregivers in the intervention and control group respectively (Table 5). On the routine immunization schedule of a child, the caregivers were requested to briefly take the researcher through the immunization schedule for a child starting from the first vaccine to the last, clearly stating the timeframes. The level of knowledge of most of the caregivers on the routine immunization for the intervention group on very high increased from $10.9 \%$ to $59.8 \%$ and from $33.8 \%$ to 37.1 in the control group before and after intervention, respectively. Likewise, the arithmetic mean of 4.44 and 2.51 on the routine immunization for the intervention and control groups respectively signified that the level of knowledge of the caregivers on the routine immunization schedule of a child was generally high amongst the intervention group ones than the control group (Table 5).

Table 5. Caregivers Level of Knowledge on Immunization

\begin{tabular}{|c|c|c|c|c|c|c|c|}
\hline \multirow[t]{2}{*}{ Statements } & & V.L & $\mathbf{L}$ & $\mathbf{M}$ & $\mathbf{H}$ & V.H & \multirow[t]{2}{*}{ Mean \pm S. D } \\
\hline & & $\mathrm{F}(\%)$ & $\mathrm{F}(\%)$ & $\mathrm{F}(\%)$ & $\mathrm{F}(\%)$ & $\mathrm{F}(\%)$ & \\
\hline \multirow{2}{*}{$\begin{array}{l}\text { Knowledge on the } \\
\text { meaning of } \\
\text { immunization }\end{array}$} & I & $0(0)$ & $1(0.3)$ & $21(5.3)$ & 91(23) & $282(71.4)$ & $4.66 \pm 0.590$ \\
\hline & C & $6(1.6)$ & $76(19.7)$ & $17(4.4)$ & $95(24.7)$ & 191(49.6) & $3.11 \pm 0.821$ \\
\hline \multirow{2}{*}{$\begin{array}{l}\text { Knowledge on at } \\
\text { least five diseases } \\
\text { that are } \\
\text { immunized against }\end{array}$} & I & $0(0)$ & $2(0.5)$ & $17(4.3)$ & 111(28.1) & $265(67.1)$ & $4.62 \pm 0.595$ \\
\hline & $\mathbf{C}$ & $0(0)$ & $79(20.5)$ & $192(49.9)$ & $18(4.7)$ & $96(24.9)$ & $3.14 \pm 0.790$ \\
\hline \multirow{2}{*}{$\begin{array}{l}\text { Knowledge on } \\
\text { when a child }\end{array}$} & I & $0(0)$ & $2(0.5)$ & $19(4.8)$ & $110(27.8)$ & $264(66.8)$ & $4.61 \pm 0.604$ \\
\hline & $\mathbf{C}$ & $0(0)$ & $74(19.2)$ & $21(5.5)$ & $88(22.9)$ & $202(52.4)$ & $3.15 \pm 0.787$ \\
\hline
\end{tabular}




\begin{tabular}{|c|c|c|c|c|c|c|c|}
\hline $\begin{array}{l}\text { should start } \\
\text { immunization }\end{array}$ & & & & & & & \\
\hline \multirow{2}{*}{$\begin{array}{l}\text { Knowledge on at } \\
\text { least five vaccines } \\
\text { that a child } \\
\text { receives during } \\
\text { immunizations. }\end{array}$} & I & $0(0)$ & $1(0.3)$ & $28(7.1)$ & $112(28.4)$ & $253(64.2)$ & $4.57 \pm 0.636$ \\
\hline & $\mathrm{C}$ & $1(0.3)$ & $17(4.4)$ & $175(45.4)$ & $82(21.3)$ & $120(31.2)$ & $3.05 \pm 0.804$ \\
\hline \multirow{2}{*}{$\begin{array}{l}\text { Knowledge on the } \\
\text { benefits of } \\
\text { immunization }\end{array}$} & I & $0(0)$ & $1(0.3)$ & $19(4.8)$ & $109(27.6)$ & $266(67.3)$ & $4.62 \pm 0.590$ \\
\hline & C & $3(0.8)$ & $97(25.2)$ & $68(17.7)$ & $81(21)$ & $136(35.3)$ & $3.05 \pm 0.837$ \\
\hline \multirow{2}{*}{$\begin{array}{l}\text { Knowledge on } \\
\text { why a child should } \\
\text { be taken for } \\
\text { immunization }\end{array}$} & I & $0(0)$ & $1(0.3)$ & $11(2.8)$ & 121(30.6) & $262(66.3)$ & $4.63 \pm 0.552$ \\
\hline & C & $1(0.3)$ & $96(24.9)$ & $199(51.7)$ & $75(19.5)$ & $14(3.6)$ & $3.01 \pm 0.775$ \\
\hline \multirow{2}{*}{$\begin{array}{l}\text { Knowledge on the } \\
\text { routine } \\
\text { immunization } \\
\text { schedule of a child }\end{array}$} & I & $0(0)$ & $12(3.1)$ & $38(9.7)$ & $108(27.5)$ & $235(59.8)$ & $4.44 \pm 0.790$ \\
\hline & $\mathrm{C}$ & $55(14.3)$ & $15(3.9)$ & $139(36.1)$ & $33(8.6)$ & $143(37.1)$ & $2.51 \pm 0.971$ \\
\hline
\end{tabular}

\section{Effects of Community-Based Interventions on Perceptions and Attitudes of Caregivers on Immunization Services}

On the nature of immunization services, there was an increase in the quality of services rendered to the caregivers from $50.8 \%$ to $95.8 \%$ in the intervention and from $58.1 \%$ to $87.1 \%$ in control before and after intervention respectively, whereas on the conduct of the health care workers when administering immunization services, the friendly conduct increased from $97.6 \%$ to $100 \%$ in the intervention and from $97.6 \%$ to $99.7 \%$ for the control before and after intervention respectively.

From the findings, all the caregivers in both the intervention group and control group never missed the immunization vaccine at any point they visited the health facilities as compared to $20.5 \%$ of the interventions and $12.8 \%$ of the controls before the intervention.

\section{Immunization Messages}

$89.9 \%$ and $79.5 \%$ of caregivers in the intervention and control received immunization messages before the intervention as compared to
$100 \%$ and $82 \%$ after intervention respectively, whereas short waiting time improved from $54.8 \%$ of the caregivers in the intervention group to $100 \%$ and from $84.9 \%$ to $99.7 \%$ of the caregivers in the control group. This shows that there was no significant difference on the caregivers' take on the waiting time before immunization services were received between the intervention and control group.

\section{Perception of Caregivers on Immunization}

The study sought to do a comparison on the caregivers' perceptions on various items on the benefits of immunization between the intervention group and the control group before and after intervention. To begin with, caregivers were asked whether they thought immunization makes children grow well. $11.7 \%$ and $95.4 \%$ of the caregivers in the intervention group and $6.8 \%$ and $27.6 \%$ of the caregivers in control believed that immunization significantly contributes to the well growth of their children before and after the intervention, respectively. Equally, arithmetic mean of 4.79 and 3.08 for the intervention and control groups respectively showed that the caregivers on the intervention group generally strongly believed that 
immunization makes children grow well while the caregivers in the control group were generally not sure whether immunization makes children grow well. The caregivers were asked whether they thought an immunized child rarely gets infected with diseases. The caregiver's belief that an immunized child rarely gets infected with diseases in the intervention group increased from $9.1 \%$ before intervention to $94.2 \%$ after intervention and from $11.2 \%$ to $26.7 \%$ in the control group, respectively. On the same note, arithmetic mean of 4.78 and 3.03 for the intervention and control groups respectively showed that the caregivers on the intervention group generally strongly believed that an immunized child rarely gets infected with diseases while the caregivers in the control group were generally not sure whether an immunized child rarely gets infected with diseases.

The caregivers were asked whether they thought immunization increases children's immunity. $9.6 \%$ and $95 \%$ of the caregivers in the intervention group and $6.8 \%$ and $22.3 \%$ of the caregivers in the control group believed that immunization increases children's immunity before and after intervention respectively Similarly, arithmetic mean of 4.79 and 2.98 for the intervention and control groups respectively implied that the caregivers on the intervention group generally strongly believed that immunization increases children's immunity while the caregivers in the control group were generally not sure whether immunization increases children's immunity. Lastly, on benefits of immunization, the caregivers were asked whether they thought immunization prevents children from getting some diseases like poliomyelitis and Tuberculosis. $8.5 \%$ and $95.2 \%$ of the caregivers in the intervention group believed that immunization prevents children from getting such diseases before and after intervention as compared to $8.1 \%$ and $29.4 \%$ of the caregivers in the control group, respectively. Equally, arithmetic mean of 4.79 and 2.99 for the intervention and control groups respectively implied that the caregivers on the intervention group generally strongly believed that immunization prevents children from getting some diseases like poliomyelitis and Tuberculosis, while the caregivers in the control group were generally not sure whether immunization prevents children from getting the same diseases.

\section{General Perception of the Caregivers on the Benefits of Immunization}

The general perception of the caregivers on the benefits of immunization services was $85.3 \%$ in the intervention group and $54.3 \%$ in the control group.

From the findings of the hypothesis test, the P-Values for $\mathbf{H}_{01}, \mathrm{H}_{02}, \mathrm{H}_{\mathbf{0 3}}, \mathrm{H}_{\mathbf{0 4}}, \mathrm{H}_{\mathbf{0 6}}, \mathrm{H}_{\mathbf{0 7}}, \mathrm{H}_{\mathbf{0 9}}$ and $\mathbf{H}_{010}$ were all greater than the level of significance, implying that we retain their null hypotheses and conclude that there is no significant difference on the uptake of BCG, POLIO-0, POLIO-1, POLIO-2, DPTHeP-Hib1, DPTHeP-Hib2, PCV1 and PCV2 immunizations between the intervention and control group. This implies that the level of uptake of BCG, POLIO0, POLIO-1, POLIO-2, DPTHeP-Hib1, DPTHeP-Hib2, PCV1 and PCV2 immunizations amongst the caregivers in the intervention and the control groups was the same. However, there was significant difference on the uptake of POLIO-3, DPTHeP-Hib3, PCV3, IPV, VITAMIN A and MEASLES immunizations between the intervention and control group. This equally meant that the level of uptake of POLIO3, DPTHeP-Hib3, PCV3, IPV, VITAMIN A and MEASLES immunizations amongst the caregivers on the intervention group and the control group differed significantly.

\section{Level of Knowledge of the Caregivers on Immunization}

The findings showed that there was a significant difference on level of knowledge of the caregivers on immunization between the intervention and control group. To justify this further, all the items on the Likert scale used to 
establish the level of knowledge between the intervention and the control group, caregivers in the intervention group demonstrated significantly higher levels of understanding about immunization as compared to the caregivers in the control group.

The results suggested that there was a significant association between the level of knowledge of the caregivers on immunization and the uptake of immunization services. This implies that the level of knowledge of the caregivers on immunization significantly influences the uptake of the immunization services. This further explains the reason as to why there was a higher level of uptake of immunization services amongst the caregivers in the intervention group as compared to their counterparts in the control group.

\section{Perception of the Caregivers on Immunization}

The findings showed that there was a significant difference on the perceived benefits by the caregivers on immunization between the intervention and control group. For all the items on the Likert scale used to establish the perceived benefits between the intervention and the control group, caregivers in the intervention group demonstrated significantly higher percentages of acknowledgement of the true perceived benefits associated with immunization presented as compared to the caregivers in the control group.

The results suggested that there was a significant association between the perceived benefits of immunization by the caregivers and the uptake of immunization services. This implies that the perceived benefits of immunization by the caregivers on immunization significantly influence their uptake of the immunization services. This additionally explains the reason as to why there was a higher level of uptake of immunization services amongst the caregivers in the intervention group as compared to their counterparts in the control group.

\section{Perceived Risks of Immunization}

The findings showed that there was a significant difference on the perceived risks of immunization by the caregivers between the intervention and control group. For all the items on the Likert scale used to establish the caregivers take on the false perceived risks of immunization between the intervention and the control group, caregivers in the intervention group demonstrated significantly higher percentages of rejection of the false perceived risks associated with immunization presented as compared to the caregivers in the control group. The results suggested that there was a significant association between the perceived risks of immunization by the caregivers and the uptake of immunization services. This implies that the perceived risks of immunization by the caregivers on immunization significantly influence their uptake of the immunization services.

\section{Discussion}

\section{Socio Demographic Information of Caregivers and their Children}

The ages of children who participated up to the end of the study were aged between 9 and 14 months old, with $50.9 \%$ of them being males. Seven children never made it up to the end of the study ( 1 in intervention and 6 in control). Whereas the ages of the caregivers who participated in the study ranged from 14 to 49 years, with the mean age of 27 years. $0.5 \%$ of the caregivers were child mothers (below the age of 18 years) Uganda's constitution only allows people aged 18 years and above to be married. According to UNICEF, Uganda is a home to 5 million child brides of which 1.3 million married before age 15 [11]. However, the mother's age, and marital status were not significant on the immunization uptake. The findings are in agreement with the study conducted in rural Abia state, Nigeria by [12], which found out that mother's age and marital status were not influential on immunization uptake. 


\section{Immunization Uptake}

The study found a statistically significant increase in post-intervention immunization uptake for most of the vaccinations in the intervention community than that in the control community. A comparison of pre- and postintervention vaccination uptake in control and intervention groups, showed that there was no significant difference in baseline immunization uptake in intervention and control groups for antigens of BCG, POLIO-0, POLIO-1, POLIO2, DPTHeP-Hib1, DPTHeP-Hib2, PCV1 and PCV2 $(P=1.00, \alpha=0.5)$. All these antigens were covered at $100 \%$. This is in disagreement with a study by [6] which found that the above antigens were not covered at $100 \%$. Qualitative study findings from health care professionals revealed that most of the mothers receive immunizations after birth (BCG and Polio 0) before being discharged from the maternity ward, but some do not bother to continue with immunization after reaching their homes. This further reinforced the observable impact of the community-based intervention on childhood immunization uptake among the intervention (97.5\%) as compared to the control group (75.1\%), and this was possible due to active community involvement in codelivering the intervention. According to [13], found out that community-based interventions increased vaccination uptake among the intervention communities more than twice than among the control communities.

Vitamin A deficiency (VAD) affects children and adults severely worldwide. Currently, the WHO estimates about 250 million pre-school going children to suffer from VAD, with the highest incidences among developing countries of in Africa. Infectious diseases, especially respiratory and diarrheal, occur among children with VAD more frequently as compared to those without VAD [14]. The study found out that there was a low uptake of Vitamin A in both study groups (83.5\% and $57.7 \%$ for intervention and control group respectively) at six months because most caregivers thought it was less important while others were not aware they were supposed to take children at six months for Vitamin A only. In Uganda, Vitamin A is given at 6 months, 12 months, 15 months, and 59 months. A study conducted in Uganda found out that vitamin A deficiency was associated with higher $43 \%$ adjusted odds of stunting among pre-school going children [15]. There is a need to improve dietary intake of vitamin A and increased coverage of vitamin A through special vitamin A supplementation program in order to improve vitamin A status of children in subSaharan Africa. It is well known that vitamin A supplementation is a highly cost-effective intervention for child health that gives a reliable source of vitamin A for pre-school children in instances of economic instability, high food prices, and inadequate dietary sources [15].

\section{Challenges Affecting Immunization Services}

Inadequate information about the importance of immunization and the need to follow immunization schedule was the major challenge affecting immunization uptake in Ntungamo district. This was revealed during key informant interviews with health care professionals where most of them (77.3\%) pointed out that most caregivers still lack information on the importance of immunization and the significance of sticking to the immunization schedule in order to get their children fully immunized.

Low turn up of mothers in bringing their children to get immunized significantly affected immunization uptake. Most health care professionals (68.2\%) stated that, despite the fact that child immunization cards given to caregivers contain dates indicating when they should be bringing their children back to health facilities for immunization, some of the caregivers still forget to turn up for the service. This is in agreement with a study conducted by [16], who found out that forgetting the days for immunization and lack of information was among various reasons mothers gave for incomplete immunization. 
The study found out that a high dropout rate was also one of the challenges affecting immunization uptake. Most health care professionals $(59.1 \%)$ stated that most mothers fail to complete the entire immunization schedule even after starting the process so well. This was majorly because most caregivers migrated to different regions before completing the immunization process making it difficult for them to keep up with the immunization schedule, Other challenges included lack of protective equipment such as gum boots and umbrellas for caregivers, especially during rainy seasons, caregivers being in religions that do not believe in immunization like "Basimuki", caregivers not minding about immunization since they believe it is not that important poor means of transport making it hard for the caregivers to access health facilities. A study by [17] also found out that migration and socio-cultural factors were among the limiting factors for immunization uptake [18]. According to EPI mobilizers the most challenge affecting the uptake of immunization services in Ntungamo district was high levels of illiteracy among the caregivers as most of the EPI mobilizers (81.8\%) stated that high levels of illiteracy among the caregivers had significantly affected immunization uptake in the sense that most illiterate caregivers lack the capacity to read on the immunization cards as to know when they are supposed to bring back their children for more immunization services hence fail to turn up.

EPI mobilizers also pointed out that vaccines running out of stock had considerably affected immunization uptake. Most of them (72.7\%) stated that lack of vaccines at the health facilities had resulted to most caregivers failing to secure immunization services for their children on the stipulated dates. This agrees with [16], who indicates that lack of vaccines on the appointment date and absence of health workers were the reasons for the low uptake of immunization services.

The distance caregivers have to travel in order to access the health facilities for immunization services had also affected immunization uptake significantly. Most EPI mobilizers (54.5\%) acknowledged that health facilities providing immunization services are inadequate, forcing the caregivers to travel long distances and incur transport costs in order to access the immunization services from the few available facilities. The findings are similar to the findings of the study by [16], which found out that longdistance walking and money were factors responsible for incomplete immunization.

The study found out that some economic activities of the caregivers had considerably affected immunization uptake. Most of the mobilizers $(54.5 \%)$ stated that economic activities such as farming had greatly affected immunization uptake due to their demanding nature. They argued that most of the caregivers opt to spend more time in farming hence focusing less on the immunization uptake of their children due to the over-demanding nature of farming. This is in line with a study conducted by [17], which found out that geographical, economic, and other socio-cultural factors tremendously affect immunization uptake.

The study also found out that high levels of poverty among the caregivers makes it difficult for them to afford the immunization services and the transport costs to the health facilities, lack of information on immunization days and locations this is attributed to the fact that most of the caregivers are illiterate $(67.5 \%$ incomplete primary school) and despite the fact that immunization dates and locations being clearly written on the immunization cards they still cannot be able to read so end up unaware, lack of transport services and the few available ones are too expensive for the caregivers, domestic violence against women making it difficult for them to focus on immunizing their children, vaccines side effects to the children, poor attitude towards immunization i.e. caregivers having negative perception towards immunization, bad weather making it difficult for the caregivers to travel to health facilities for immunization and long waiting hours due to few 
health workers and few health facilities administering immunization services. This is in conformity with a study by [13] which found out that common barriers to immunization uptake included recent migration (which could be associated with lack of awareness of local facilities), misplaced vaccination cards, difficulties in accessing vaccination facilities or negative attitudes towards immunization.

Inadequate facilitation from the government had considerably affected health facilities in administering immunization services to caregivers. Most health care professionals $(63.6 \%)$ stated that the facilitations they receive from the government cannot address all the issues pertaining to immunization uptake. They stated that the financial support from the government is inadequate to support EPI activities, making it hard for them to effectively administer immunization services to caregivers. This is in line with a study conducted by [6] which found out that long distances, inadequate transport facilitation, vaccine stock-outs and geographical terrain were barriers affecting effective immunization uptake. Few numbers of immunization outreaches had also significantly affected health facilities in administering immunization services. Most of the health care professionals $(59.1 \%)$ stated that the already few immunization outreaches are so overwhelmed hence failing to serve the visiting caregivers efficiently. They attributed this to a lack of adequate funding by the government to support establishment of more outreaches. This is also in conformity with the findings by [6].

Low morale among staff on static immunization has considerably affected immunization uptake in health facilities. Most health care professionals (59.1\%) acknowledged that staff within the health facilities are demoralized due to poor working conditions in terms of remunerations and inadequacy of resources such as personal protective equipment and vaccines.

Cold chain maintenance is important in ensuring effective immunization services in any country. Ntungamo district still possess vaccine fridges that utilize solar power, electricity, and gas, creating challenges when grid power is off or when gas is over or during bad weather for solar fridges.

The study found out that facilities do poses faulty vaccine fridges due to being either old or lack of proper maintenance by cold chain technicians, affecting immunization uptake. A study conducted by [19], in 10 countriesEthiopia, Nigeria, Kenya, Malawi, Tanzania, Uganda, Cameroon, Mozambique, Lesotho and India, found out that lack of effective monitoring, inadequate resources, lack of upgrade to the latest cold chain technology, incompetent cold chain technicians and lack of spare parts were challenges affecting cold chain maintenance in developing countries.

Poor mobilization of caregivers due to insufficient funding for EPI mobilizers, poor cold chain maintenance due to factors like bad weather for solar vaccine fridges and inadequate gas cylinders and poor supply of grid power and understaffing majorly due to low health wage bill to support HRH recruitment potentially contributes to low immunization uptake. Failure to follow the routine immunization schedule came out as a challenge affecting immunization uptake, $34.3 \%$ of the caregivers were not conversant with the correct routine immunization schedule for their children based on the responses they gave while $29.6 \%$ of them had no idea on the routine immunization schedule of a child. However, for a child to receive maximum protection against vaccine preventable diseases, all immunizations should be received within a recommended time interval [13].

\section{Level of Knowledge on Immunization}

Knowledge of caregivers is another factor which affects the immunization uptake, and these include knowledge and attitude towards immunization and vaccines. Knowledge on immunization were very high among caregivers in the intervention group than the control group 
at $68.8 \%$ and $4.2 \%$, respectively. The level of knowledge was significantly associated with immunization uptake $(\mathrm{P}=0.00, \alpha=0.5)$. The findings are in line with the study conducted in Nigeria on determinants of immunization status among children in a rural area which showed that mothers of higher knowledge score fully immunized their children as compared to those of lower knowledge on immunization [20].

The benefits that caregiver attaches to immunization greatly influences the immunization status of the children. The high immunization coverage observed among the intervention group than the control group could be explained as a beneficial factor that caregivers attached to the immunization since most of the caregivers in the intervention group $(85.3 \%)$ regarded immunization as very highly beneficial to their children while most of the caregivers on the control group (54.3\%) regarded the services as moderately beneficial to their children. Most of the caregivers in the intervention group $(84.6 \%)$ believed that immunization increases children's immunity, while most of the caregivers in the control group (47\%) were not sure whether immunization increases children's immunity. A higher percentage of caregivers in the intervention group also believed that an immunized child rarely gets infected with diseases and possess higher immunity than unimmunized as compared to the control group. This explains the reason why the intervention group had a higher immunization coverage than the control group. The findings are similar to the study by [18], who found out that maternal knowledge was a factor influencing immunization of children under five years. Knowledge on the benefits of immunization was significantly associated with the immunization uptake $(\mathrm{P}=0.00, \alpha=0.5)$.

\section{Effect of Community-Based Intervention on Immunization Uptake}

In Uganda, a fully immunized child is expected to have received one dose of Bacillus Calmette-Guerin (BCG) and polio zero at birth or soon after, 3 doses each of diphtheria, pertussis, and tetanus (DPT) and oral polio vaccine $(\mathrm{OPV})$ vaccines at 6,10 , and 14 weeks, and one dose of measles vaccine (at 9 months or soon after) [21] Vaccines introduced more recently and administered during the first year of life include hepatitis $\mathrm{B}$, pneumococcus, and rotavirus vaccines. In addition, vitamin $\mathrm{A}$ is administered at 6 and 12 months [21] As part of the Polio Eradication and Endgame Strategic Plan, inactivated polio vaccine was introduced in the routine immunization schedule in 2016, with switch from trivalent to bivalent polio vaccine [22]. There was a statistically significant difference in the immunization uptake between the intervention and control groups $(\mathrm{P}=0.00, \alpha=$ 0.5). Complete immunization uptake was at $97.5 \%$ in the intervention group as compared to $75.1 \%$ in the control group. The difference was significantly associated with the communitybased intervention $(\mathrm{P}=0.00, \alpha=0.5)$. The improvement of immunization uptake in the intervention group was attributed to communitybased interventions, which included training of village health teams (VHTs), health education of caregivers, training of health workers, preparation of outreach sites and reminding of caregivers on immunization days. The results are in agreement with the findings of [13], who found out that community-based interventions increased vaccination uptake, and the likelihood of full immunization by the age of 1 year was more than twice among the intervention than the control groups.

The study found out that DPTHeP-Hib3 and Measles coverage in Ntungamo district was at $93.2 \%$ and $86 \%$, respectively. Uganda's national immunization program (UNEPI) recommends $90 \%$ and $95 \%$, respectively. A study conducted in Hoima district in Uganda also found that DPTHeP-Hib3 uptake was higher than measles uptake at $81 \%$ and $65.5 \%$, respectively [6]. This may be the reason why Ntungamo district has not had measles outbreaks like most of the other district in Uganda since its uptake is higher compared to other districts. 


\section{Conclusion}

From the above results and discussion, the following conclusions have been made:

1. There was no statistically significant difference between BCG and Polio 0 in intervention and that of the control group at the baseline study. In the intervention group, the uptake of immunization increased more than the control group after intervention.

2. At baseline, the level of knowledge on immunization services was higher among the control group than the intervention group. After the intervention, the knowledge improved in the intervention group than the control.

3. Caregivers' knowledge on immunization services was significantly associated with the immunization uptake.

4. Socio-cultural and economic factors like religion, poverty, illiteracy, and inadequate knowledge on immunization were some of the factors for the low uptake of immunization services.

5. The community-based interventions were effective in increasing the immunization uptake in the intervention group.

\section{Recommendations}

\section{Implementing Agency (District/ Ministry of Health)}

1. The health facility in charges should liaise with the district cold chain assistant who is in charge of the immunization programme to ensure a regular supply of vaccines at all times.

2. The district health office, in consultation with the Ministry of Health, should consider increasing the percentage of immunization on the PHC vote in order to cater for increasing demands of immunization at the health facility level.

3. It is recommended that the Ministry of Health should provide resources to train and motivate VHTs to work as a resource person for immunization programme at grass root levels. Remind caregivers for on immunization dates, prepare for outreaches and give health education messages.

4. In order to increase immunization uptake, the district health officer should prioritize immunization activities in the health sector budget to support all health assistants at health facility levels to do mobilization and support VHTs.

5. It is recommended that health facility management committees support EPI focal persons at facility levels to conduct immunization outreaches regularly out missing, missing immunization sessions by health workers increase immunization dropout rates.

\section{Recommendation for Further Study}

There is a need to conduct a health facilitybased study to rule out the influence of vaccination staff motivation.

\section{Acknowledgment}

We would like to thank Ntungamo District local Government for allowing us to conduct the study in their district. We also wish to thank the communities of Ruhaama and kajaara counties for their support during the study.

\section{Competing interests}

The authors declare no conflict of competing interests.

\section{Authors' contributions}

BT conceived and designed the study, collected, and analysed data and drafted the manuscript. EG contributed to the conception and design of the study, assisted in data interpretation and revision of the manuscript for intellectual content. MK contributed to the conception and design of the study, assisted in data interpretation and revision of the manuscript for intellectual content.

\section{Funding}

The study was privately funded and is part of the PhD study for BT. 


\section{References}

[1] M. M. Davis and S. K. Shah (2019), "Outbreaks of vaccine-preventable diseases: responding to system failure with national vaccination requirements," Jama, vol. 322, no. 1, pp. 33-34.

[2] WHO and UNICEF (2018) Estimates of Immunization Coverage: 2018 Revision.

[3] "UDHS" (2016). Uganda Demographic and Health Survey

https://www.google.com/search?q=UDHS.+Uganda +Demographic+and+Health+Survey.

[4] "Uganda MoH" (2013). Annual Health Sector Performance Report. healthgoug/docs/AHSPR. https://www.google.com/search?q=Uganda+MoH.+ Annual+Health+Sector+Performance+Report.

[5] "Ministry of Health Uganda". Health sector strategic plan III 2010/11-2014/15. https://www.google.com/search?q=Ministry+of+He alth+Uganda.+Health+sector+strategic+plan+III+20 10 .

[6] O. O. Malande et al. (2019), "Barriers to effective uptake and provision of immunization in a rural district in Uganda," PloS One, vol. 14, no. 2, p. e0212270.

[7] E. K. Wakida et al. (2019), "Implementing clinical guidelines to promote integration of mental health services in primary health care: a qualitative study of a systems policy intervention in Uganda," Int. J. Ment. Health Syst., vol. 13, no. 1, pp. 1-14.

[8] Awadh, M. A. et al. (2014), "Does an educational intervention improve parents' knowledge about immunization? Experience from Malaysia," BMC Pediatr., vol. 14, no. 1, pp. 1-7, 2014.

[9] M. Johri et al. (2015), "Interventions to increase immunisation coverage among children 12-23 months of age in India through participatory learning and community engagement: pilot study for a cluster randomised trial," BMJ Open, vol. 5, no. 9, p. $\mathrm{e} 007972$.

[10] Y. Hu, Y. Chen, Y. Wang, Q. Song, and Q. Li, (2017) "Prenatal vaccination education intervention improves both the mothers' knowledge and children's vaccination coverage: Evidence from randomized controlled trial from eastern China," Hum. Vaccines Immunother., vol. 13, no. 6, pp.14771484.
[11] V. H. Mlambo, M. V. Hlongwa, and L. Msthalui, (2019) "The implications of child marriages and their developmental effects on young girls/women in sub- Saharan Africa," Afr. Renaiss., vol. 16, no. 2, pp. 75-99.

[12] E. E. Nwokocha and C. Obioma, (2016), "Social and cultural factors influencing immunization of children in rural Abia State, Nigeria."

[13] P. Sengupta, A. I. Benjamin, P. R. Myles, and B. V. Babu, (2017), "Evaluation of a communitybased intervention to improve routine childhood vaccination uptake among migrants in urban slums of Ludhiana, India," J. Public Health, vol. 39, no. 4, pp. 805-812.

[14] R. R. Penkert et al. (2019), "Influences of vitamin A on vaccine immunogenicity and efficacy," Front. Immunol., vol. 10, p. 1576.

[15] P. Ssentongo et al. (2020), “Association of vitamin A deficiency with early childhood stunting in Uganda: A population-based cross-sectional study," PLoS One, vol. 15, no. 5, p. e0233615.

[16] M. A. Yousif, A. A. Albarraq, M. A. A. Abdallah, and A. I. Elbur (2013), "Parents' knowledge and attitudes on childhood immunization. [17] Okueso Samuel and O. Kayode (2019), "Sociocultural factors as Predictor of Immunization Participation among Rural Mothers of Waterside in Ogun State, Nigeria”.

[18] N. Galadima, N. A. M. Zulkefli, S. M. Said, and N. Ahmad (2021), "Factors influencing childhood immunisation uptake in Africa: a systematic review," BMC Public Health, vol. 21, no. 1, pp. 1-20.

[19] "Improving cold chain systems: Challenges and solutions.

https://www.google.com/search?q=Improving+cold +chain+systems $\% 3 \mathrm{~A}+$ Challenges+and+solutions.

[20] O. Olumuyiwa, F. A. Ewan, P. M. Francois, and I. A. Vincent (2008), "Determinants of immunization status children in rural Nigeria," BMC Public Health, vol.8, no. 381, pp. 4-8.

[21] "Immunization Guidelines by Unepi https://www.google.com/search?q=Immunization+G uidelines+By+Unepi.

[22] UNEPI (2019). Immunization- guidelines. https://www.health.go.ug/wp. 